\title{
Research on the Teaching Model of Curriculum Thought and Politics Based on the Core Ideological and Political Literacy of Military Cadets
}

\author{
Fang Hua $^{\text {la }}$, Tian Yanhui ${ }^{1 b}$, Lei Desheng ${ }^{1 \mathrm{c}}$, Du Keke ${ }^{\text {ld }}$

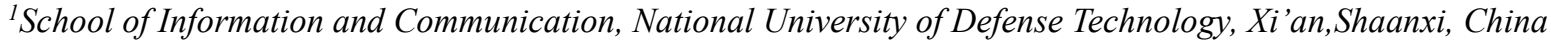 \\ a819283781@163.com \\ b*tianyanhui05@163.com \\ c278870421@qq.com \\ d48059821@qq.com
}

\begin{abstract}
Promoting the construction of curriculum thought and politics comprehensively was a strategic measure to carry out moral cultivation and cultivate personnel for war, and it was the objective requirement of training high-quality and specialized new military talents, also it was the "casting soul" project of military academies. We had put forward that, the key to solve the practical problems in the military academy is to combine the special characteristics of education and the educational characteristics of the new era and aim at the core ideological and political literacy of cadets, finally, exploring a general and extensible curriculum thought and politics teaching model. In this paper, we construct the content system of the core ideological and political accomplishment of military cadets in the new era from three aspects: political accomplishment, professional accomplishment and moral accomplishment, so that it had a clear goal for curriculum thought and politics of military academy, then putting forward the "1161" thought and Politics teaching model of military academy curriculum.
\end{abstract}

Keywords: Core ideological and political literacy, Curriculum thought and Politics, Teaching mode

\section{基于军校学员核心思政素养的课程思政教学模式探究}

方 华 $1, \mathrm{a}$ 田艳辉 $1, \mathrm{~b}^{*}$ 雷德胜 $1, \mathrm{c}$ 杜柯柯 $1, \mathrm{~d}$

1 国防科技大学信息通信学院, 西安, 陕西, 中国

la819283781@163.com

b*tianyanhui05@163.com

c278870421@qq.com

d48059821@qq.com

\section{摘要}

全面推进课程思政建设是落实立德树人、为战育人的战略举措, 是培养高素质、专业化新型军事人才的客观要 求, 是军队院校的 “铸魂” 工程。笔者提出, 军校开展课程思政, 破解现实难题的关键在于结合军校自身育人 特殊性与新时代教育特点, 瞄准军校学员核心思政素养, 探索可通用、可推广的课程思政教学模式。论文从政 治素养、职业素养、品德素养三个方面构建起新时代军校学员核心思政素养内容体系, 使军校课程思政“同向” 有了明确的目标, 继而提出 “1161”军校课程思政教学模式。

关键词：核心思政素养，课程思政，教学模式 


\section{1. 前言}

习主席指出, 其他各门课都要守好一段渠、种好 责任田，使各类课程与思想政治理论课同向同行，形 成协同效应。何谓 “同向同行” ? 这是首先须明确的 基本理论问题。笔者认为, 就是在为党育人、为军育 才育视阈下, 其他课程与军校政治理论课至少在三个 向度要保持一致。即国家政治方向认同、军队育人方 向认同、军人核心价值观认同。而这三者集中体现在 军校学员的核心思政素养培育目标上。由此, 我们认 为, 军校课程思政建设之要在于瞄准军校学员核心思 政素养, 推广可通用课程思政教学模式。

\section{2. 关于新时代军校学员核心思政素养的探讨}

军校学员作为部队建设的新鲜血液与骨干力量, 其核心思政素养培育伴随我军军队院校发展的历史 经历了一个不断演进的过程。军校学员核心思政素养, 在新民主主义时期集中体现为爱国爱民与为革命奋 不顾身的情怀。在社会主义革命与建设时期集中体现 为忠诚于党、崇尚荣誉的价值追求。在改革开放和社 会主义现代化建设时期集中体现为当代革命军人核 心价值观的五句话要求。

在中国特色社会主义新时代, 以习近平同志为核 心的党中央统筹国际国内两个大局, 贯彻党的基本理 论、基本路线、基本方略, 统筹国内国际两个大局, 统揽伟大斗争、伟大工程、伟大事业、伟大梦想, 擘 画政治建军、改革强军、科技强军、人才强军、依法 治军方略, 引领军队重整行装再出发, 推动国防与军 队建设取得了历史性成就, 发生历史性变革。当前, 面对国际国内新形势, 面对军事院校办学治校新特点, 面对学员成份新变化, 军校学员核心思政素养内涵理 应因时而进、因势而新, 有着更加丰富的内涵与时代 要素, 需要更清晰的界定与表达, 以适应履行职能使 命、建成世界一流军队的现实需求。同时军校学员思 政素养内容体系的明晰也是军校开展课程思政建设 的逻辑起点, 只有明确了 “育” 的目标, 立起了靶子, 课程思政的着力点才更清晰与明确, 标准才能落地 ${ }^{[1]}$ 。

新时代军校学员核心思政素养的内涵建设, 必须 坚持习近平强军思想固魂育人这一指导, 坚持守正创 新, 着眼国防和军队现代化目标任务、聚焦服务备战 打仗这一根本、围绕永葆革命军人本色使命职能, 立 足学员实际、遵循价值观培育规律, 把四有新时代革 命军人作为人才培养的总目标。

本着这些根本性的原则, 按照《军队思想教育规 定》要求的 “培养听党指挥的接班人、砥研能打胜仗 的战斗队、塑造作风优良的子弟兵” 的育人标准, 笔 者认为新时代军校学员核心思政素养应当包括政治 素养、职业素养、品德素养三方面, 从 “听党指挥、 能打胜仗、作风优良”三个维度来展开构建。

\section{1. 以听党指挥为主的政治素养}

习主席在庆祝中国共产党成立 100 周年大会上 深刻指出, 坚持党指挥枪、建设自己的人民军队, 是 党在血与火的斗争中得出的颠扑不破的真理。90 多 年来, 我军之所以是一支拖不垮、打不烂的钢铁雄师, 铸牢军魂是根本所在。毛泽东同志把“坚定正确的政 治方向”作为抗大的第一条校训, 邓小平同志曾强调 “毫无疑问, 学校应该永远把坚定正确的政治方放在 第一位”。当前, 敌对势力在意识形态领域对我军的 渗透破坏不遗余力, 铸魂与“蛙魂”的较量十分激烈。 学员是军事人才的重要储备, 是一线工作和未来战争 的指挥者、实施者、组织者，政治合格居于思政素养 体系之首。新时代军校育人, 要把提升学员政治素养 摆在首要位置。

在政治信念层面, 自觉用习近平新时代中国特色 主义思想和习近平强军思想武装学员头脑, 牢固树立 四个意识、坚定四个自信, 做到两个维护, 就是要铸 牢军魂, 培养听党指挥的接班人。

在政治属性层面, 引导学员懂得党与军队之间有 着天然的联系, 只有坚定跟党走, 才能确保军队建设 发展正确的政治方向、才能确保党和国家的事业兴旺、 前途光明。就是要夯实军校学员听党话、跟党走的思 想政治根基。

在政治能力层面, 要培养学员对党的情感认同, 做到坚定做到听党指挥。自觉抵制西方敌对势力企图 对我 “分化” “西化” 的战略图谋, 立场鲜明地批驳 “军队非党化、非政治化” 和 “军队国家化” 的荒谬 观点, 坚定维护党对军队绝对领导的一系列制度与原 则, 坚决完成党和人民赋予和各项任务。

听党指挥涵盖政治信念、政治属性、政治能力 3 个二级指标及 11 个三级指标，(如图 1 所示)

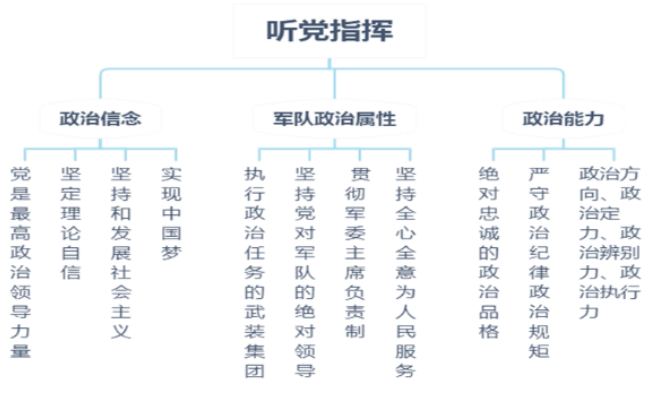

图 1 核心思政素养之素养模型图

\section{2. 以能打胜仗为主的职业素养}

军校学员职业素养是指通过军校与部队的培养, 产生并具备的对职能使命、战争指导、练兵备战的深 度认知并自觉践行的综合品质。军队因打仗而生, 军 人生来为战胜。能打胜仗是军队存在的根本价值, 能 打胜仗是党和国家对全体军人的基本职业要求。向战 
而行, 保证打赢是育人的根本价值所在, 也是检验军 校育人成效的根本标准。培养向战为战的人才，锻造 能打胜仗的战斗队，应当是军校课程思政的重要内容。

在想打仗层面, 夯实学员向战为战的思想根基。 围绕主责主业, 强化服务备战打仗的鲜明指向。引导 学员勇担新时代职能使命, 破除和平积弊, 树牢人民 军队永远是战斗队思想、随时准备打仗的思想, 把战 斗力标准在军校立起来、落下去, 全面归正育人重心。

在谋打仗层面, 通过课程思政加强对战争理论的 指导。教员应以战统教, 教战研战, 立起实战化教学 的鲜明导向。引导学员在正确理解职业特殊政治要求 的基础上, 让学员树立马克思主义战争观、理解把握 军队战略部署, 理解改革是制胜未来的关键, 掌握信 息化战争规律与特点, 主动研究信息化战法与技能, 按照强军为战的时代要求, 提高院校育人对打仗的贡 献率，做到育人工作全面向打仗聚焦用劲。

在能打仗层面, 所有课程瞄准练兵备战, 聚力研 战为战, 坚持实战实训, 着力培育学员两不怕战斗精 神。坚持平战一体, 各级议教突出学员实战能力培养, 三全育人与作战训练目标一体推进, 组教施训模式与 部队战备状态相互匹配。

能打胜仗涵盖职能使命、战争理论、练兵备战 3 个二级指标及 13 个三级指标, (如图 2 所示)

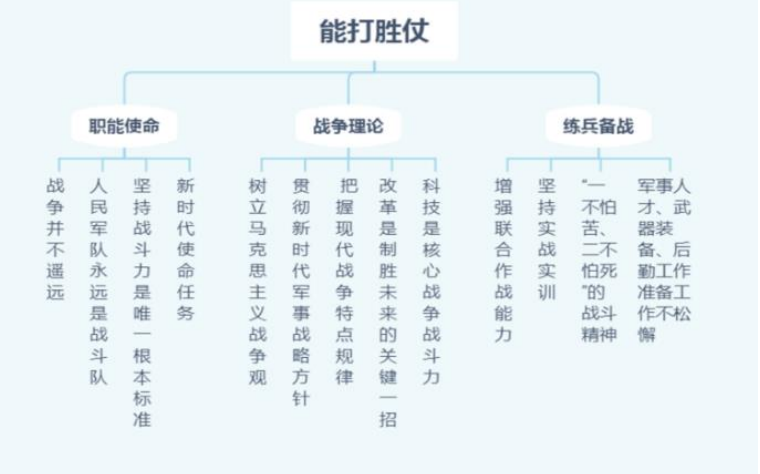

图 2 核心思政素养之职业素养模型图

\section{3. 以作风优良为主的品德素养}

在长期革命与建设的实践中, 我军形成了特有的 光荣传统和优良作风, 这些严明的纪律与优良的作风 对人具有潜移默化的影响, 使得我军性质宗旨本色始 终不变、不断从胜利走向新的胜利。能否自觉弘扬人 民军队光荣传统和优良作风、传承红色基因, 是关系 军队建设的根本问题。军校育人, 重在塑造永葆政治 本色、作风优良的人民子弟兵。

在政治本色层面, 所有课程用不同的方式让学员 理解军政军民团结、尊干爱兵、官兵一致、艰苦奋斗 是我军的政治本色, 是我军过去、现在和未来的制胜 法宝。要自觉学传统、爱传统、讲传统, 永葆艰苦奋 斗本色, 确保红色基因代代传 ${ }^{[2]}$ 。
在军人操守层面, 军校各门课程教学要通过挖掘 历史、用好典型、讲活故事等方式，让学员懂得人民 军队是党绝对领导下的有着高度政治觉悟的雄师劲 旅, 要履行新时代使命任务, 必须不怕牺牲、甘于奉 献, 视荣誉如生命、树立坚定的理想信念、正确的价 值理念、崇高的道德观念。

在严实作风层面, 使学员理解严实为治军之要、 只有依法治军、从严治军、纪律严明才能出战斗力, 理解党中央、中央军委坚定不移正风肃纪反腐的信心 与决心, 引导学员自觉贯彻全面从严治军要求, 用铁 的纪律凝聚铁的意志、锤炼铁的作风、锻造铁的队伍。 自觉立起带兵人的好形象、好样子。

作风优良涵盖政治本色、军人操守、严实作风 3 个二级指标及 12 个三级指标，（如图 3 所示）

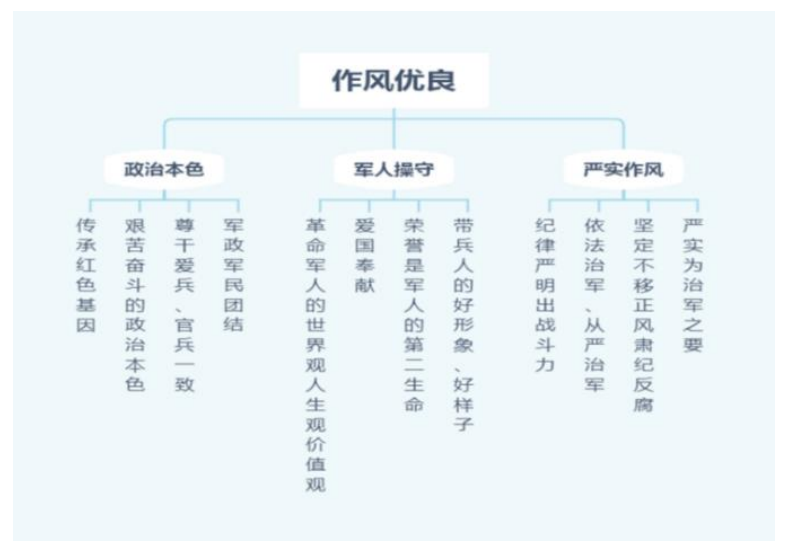

图 3 核心思政素养之品德素养模型

\section{3. 基于军校学员核心思政素养的课程思政教 学模式}

课程思政由于内在的规律性和统一的要求, 应该 有一种或者若干种的典型教学模式可供借鉴。本文力 图把握军校课程思政建设的规律、特点, 探讨基于军 校学员核心思政素养的具有可推广价值的课程思政 教学模式, 以提高育人质效。

\section{1. 构建理念}

构建理念是对两种代表性观点的辨析中得来的。 一是对建模意见的不统一。经常有教员提出疑问, 如 果军校课程思政提出一种固定教学模式, 会不会失去 多样性, 束缚教员的手脚, 不利于课程思政建设沿着 个性化方向发展, 影响 “百花齐放、百家争鸣” 地局 面。当然也有很多赞同、支持者, 认为统一的教学模 式有利于推动当前课程思政建设, 保证课堂基本教学 质量。笔者认为, 军校课程思政建设是当前与未来军 校思想政治建设的重点任务。虽然 “有模式但不应唯 模式” “教无定法、是为至法, 教学有法, 贵在得法” 但真正掌握课程思政内核并能娴熟运用教学艺术的 教员毕竟是少数, 多数教员对思政育人领域不甚熟悉, 当前提前提出一个教学建设模式参考是较为合适的。 
模式的功能首先是规范军校非思政课程建设的标准 问题, 依什么来建, 按什么标准建, 这是很基础且十 分重要的问题。

二是关于教学模式重点在哪里。关于教学模式, 有几种不同代表观点。有的教员提出应该把重点放在 课程思政教学活动的程序上, 强调“五要素三性”说, 即应具有理论依据、教学目标、操作程序、实现条件 和教学评价, 应包括指向性、操作性与稳定性三个特 点。有的教员则认为, 教学模式应为内容服务, 如何 更好地实现课程思政教学目标是唯一标准。有的教员 强调模式的重点应是启发大家创新课堂教学方法, 解 决当前课程思政教学方法单一的问题。我们认为, 研 究建模的初衰是为了在军校加快推进工程化、系统化 课程思政建设步伐, 提供一种可行的教学建设思路。 因此它应该是偏程序与步骤的, 对于教学方法会有所 涉及, 但因为试点课程的局限性, 也许不能覆盖所有 课程特点。

因此, 论文所研究的教学模式构建理念应是一一 以新时代军校学员核心思政素养为起点, 遵循 “同向 同行” 的核心理念, 以基础课与专业课程为对象, 以 鼓励其他课程教员全员参与、实践课程思政、挖掘学 科自身价值为动力, 以 “合作、探究、实践、验证” 为主要构建路径, 以课堂教学为实践平台、以科学评 价为指引, 促进军校课程思政战略全面落地、整体提 升。

\section{2. 构建原则}

构建原则是教学模式构建过程中应该坚持的准 绳。只有明确原则, 才能保证教学模式的正确方向与 科学性。

\section{2.1 与军校学员核心思政素养相一致的原则}

军校学员核心思政素养集中体现了新时代军校 学员应有的政治、职能、道德要求, 集中体现了党对 军人价值定向的时代标准、是国家和人民对新时代青 年的价值期待在军队的特殊展开、是新时代军校思想 政治教育的目标。坚持与军校学员核心思政素养相一 致的原则, 就是在构建军校课程思政教学思政教学模 式时以它为起点, 作为人才培养方向性的建设标准, 任何一门课程建设都须把教学目标设计、课程思政元 素库建设、课程教学案例库建设、教材建设、示范课 与微课建设、教学评价都置入这一座标体系中加以权 衡、比较和判断, 研判是否相一致、是否可行、能否 做到同向同行 ${ }^{[3]}$ 。

\subsection{2 以学员为中心的原则}

不论是哪一种教学模式, 如果不能发挥学员的主 观能动性, 不去遵循学员的接受规律、不扭住学员的 学习过程、不能突出学员主体地位, 毫无疑问就是不 成功的, 就不能提高人才培养质效。坚持以学员为中
心的原则, 一是要坚持以正面教育为主。充分信任、 尊重和发动学员, 着力抓积极因素, 讲正面道理, 注 重启发自我教育, 调动学员自身内在的积极因素去克 服消极因素; 二是要教学内容充分满足学员需要。考 虑学员所思所想, 兼顾思想性与时代性。既坚持思想 引领, 又要在内容的表达上下功夫, 与时代同频共振, 用 “流行的” 表达 “笃行” 的; 三是教学过程设计要 围绕学员学习过程展开。教学过程设计要贴合学员学 习特点, 同时运用自身的学识与人品成为学员信赖的 人, 提高学员积极性和学习效果; 四是教学方式方法 要贴近学员。实践模拟、交流研讨、BOPPPS、翻转 课堂、感悟分享、启发诱导、情境创设、沙盘推演、 任务驱动、参观见学这些学员易于接受的方法都可以 成为课程思政教学的有力推手 ${ }^{[4]}$ 。

\subsection{3 可推广性的原则}

如果一种课程思政教学模式只是无缝贴合自己 课程特点, 而不具备可复制性与推广的前景, 那么它 的价值是有限的。我们试图遵循一定的教育规律、按 照一定的目标要求, 对所要研究的对象进行方法论意 义上提取与抽象。期待构建课程思政的基本教学模式, 并在某一门或某几门课程当中应用和验证, 最终能够 为所有军校非政治理论课程开展课程思政提供有益 借鉴。

\subsection{4 可发展性的原则}

可推广性与可发展性并不矛盾。可推广性指的是 教学模式可以为军校课程开展课程思政提供方法论 意义上的指导。可发展性是指在既有可供统一操作、 上手容易的基础模式上，体会基本精神，又可结合自 己学科特点, 发展属于自己学科更为具体、更为独特 的学科课程思政教学模式。

\section{3. 教学模式内容}

遵循上述理念与四条原则, 结合基地课程思政试 点课程实践, 我们探索构建了基于军校学员核心思政 素养的 1161 课程思政教学模式 (如下图所示), 并在 用模与研模的过程中不断修正与完善。

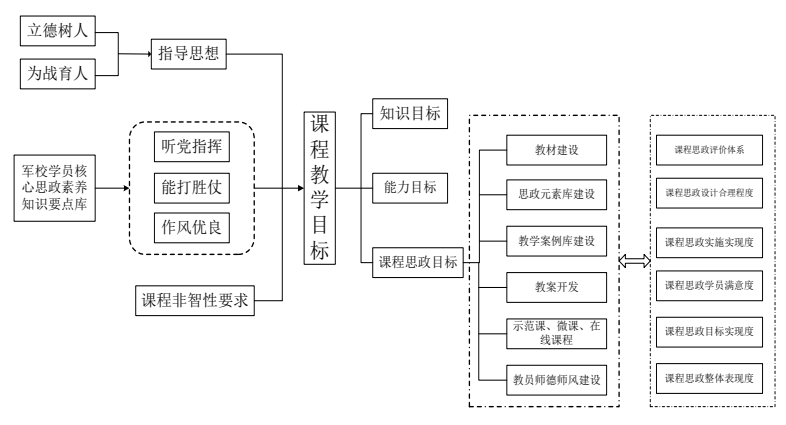

图 41161 军校课程思政教学模式

1161 教学模式可概括为: (1)围绕 1 核心, 即围绕 军校学员核心思政素养; (2)明确 1 目标, 即明确课程 
教学目标中的课程思政目标; (3)建设 6 维度, 即扭住 课程思政的教材建设、教案设计、元素库、教学案例 库、示范课与微课建设, 教员自身思政素养提升六个 关键环节; (4)用好 1 评价, 即运用评价来提升课程思 政建设质效。图示能够较为清晰地反应各者之间的逻 辑关系。

“立德树人、为战育人”是新时代军校育人的“纲” 和“魂”, 课程思政建设也须以此为指导。军校开展课 程思政建设,需要与政治理论课育人方向与目标同向 同行，因此需要明确“听党指挥、能打胜仗、作风优 良”为中心的新时代军校学员核心思政素养, 并结合 军校政治理论课教学大纲要求、深入贯彻习近平强军 思想, 建设军校学员核心思政素养知识要点库, 为基 础类、专业类课程开展课程思政建设提供有益借鉴 ${ }^{[5]}$ 全面贯彻新时代军事教育方针、以新时代军校学员核 心思政素养为准绳, 结合课程自身特点, 系统梳理学 科非智性要求, 制订课程教学目标。

教学目标应当含盖知识目标、能力目标以及课程 思政目标。实现课程思政目标, 在实操层面必须从教 材建设、思政元素库建设、教学案例库、体现课程思 政设计的教案开发、示范课微课与在线课程建设、教 员师德师风建设六个方面着力。要确保这一教学模式 的建设开放性与质效良性上升, 还需要依托科学的军 校 “三性六度” 课程思政评价体系。即导向性、开放 性、有效性, 课程思政设计合理度、课程思政整体表 现度、课程思政实施体现度、课程思政学员满意度、 课程思政目标实现度、课程思政资源建设度。课堂环 节是课程思政实效的重点呈现, 从操作程序上看, 关 键要抓好三个阶段。注重课前挖掘与规范一一开展集 体备课, 建设基于校学员核心思政素养的课程思政元 素库与教学案例库。做好课中融入与渗透——教员精 心选择知识点和案例, 结合课程特点, 一体化设计、 创新方法、打造充满获得感的精品课堂。坚持课后巩 固与内化一一跟踪学员学习效果, 同时在学员与专家 双主体的评价反馈基础上, 优化教学设计, 调整教学 细节, 稳步提升课程思政开展质效。

\section{4. 结论}

厘清军校学员核心思政素养的构成要素是基于 军校学员核心思政素养的课程思政教学模式改革的 逻辑起点和基础。本研究认为, 军校学员核心思政素 养既有与地方大学生相似的要素, 又有特殊部分, 大 致可以分为以听党指挥为主的政治素养、以能打胜仗 为主的职业素养和以作风优良为主的品德素养, 在此 基础上, 本研究进一步提出了课程思政教学模式改革 的理念、应遵循的原则和具体的教学模式内容。研究 结论可为军校课程思政教学模式改革提供一定的思 路和借鉴。

\section{项目基金}

本文为国防科技大学校内教学研究课题 《基于军校学员核心思政素养的课程思政教 学模式研究》(U2019032)的阶段性成果之一。

\section{REFERENCES}

[1] Dai Shiying. (2021) Research on the strategies of improving the Ideological and political Ability of Professional teachers in Colleges and Universities. Modern trade and industry,42:80-81.

[2] Tian tian, Zheng Chunhua, Kang Jin.(2021) Exploration of "Course ideological and political" teaching of economic mathematics in Higher Vocational Colleges.Modern vocational education, 45:44-45.

[3] Qu Juan. Practical research on the integration of higher Vocational mathematics into "Curriculum Ideology and Politics".(2021) Modern vocational education, 45:214-215.

[4] Luo Beizhan. Research on ideological and Political Construction of Chinese Traditional Culture course in Higher Vocational Colleges.(2021) Guangxi Normal University. pp. 31-34.

[5] Song Hongna. Research on the content construction and teaching application of ideological politics in High school physics Curriculum. (2021) Hebei Normal University. pp. 56-58. 